\title{
Detection of Candida species resistant to azoles in the microbiota of rheas (Rhea americana): possible implications for human and animal health
}

\section{Correspondence}

Raimunda Sâmia Nogueira

Brilhante

brilhante@ufc.br
Received 3 December 2012 Accepted 10 March 2013
Raimunda Sâmia Nogueira Brilhante, ${ }^{1}$ Lucas Pereira de Alencar, ${ }^{1,2}$ Rossana de Aguiar Cordeiro, ${ }^{1}$ Débora de Souza Collares Maia Castelo-Branco, ${ }^{1}$ Carlos Eduardo Cordeiro Teixeira, ${ }^{1}$ Ramila de Brito Macedo, ${ }^{1}$ Daniel Teixeira Lima, ${ }^{1}$ Manoel de Araújo Neto Paiva, ${ }^{1,2}$ André Jalles Monteiro, ${ }^{3}$ Nilza Dutra Alves, ${ }^{4}$ Moacir Franco de Oliveira, ${ }^{4}$ José Júlio Costa Sidrim, ${ }^{1}$ Marcos Fábio Gadelha Rocha, ${ }^{1,2}$ Tereza de Jesus Pinheiro Gomes Bandeira ${ }^{1,5}$ and Terezinha de Jesus Santos Rodrigues ${ }^{1}$

\footnotetext{
${ }^{1}$ Department of Pathology and Legal Medicine, School of Medicine, Specialized Medical Mycology Center, Postgraduate Program in Medical Microbiology, Federal University of Ceará, Fortaleza, CE, Brazil

${ }^{2}$ School of Veterinary, Postgraduate Program in Veterinary Science, State University of Ceará, Fortaleza, CE, Brazil

${ }^{3}$ Department of Statistics and Applied Mathematics, Federal University of Ceará, Fortaleza, CE, Brazil

${ }^{4}$ Department of Animal Science, Federal Rural University of the Semiarid, Mossoró, RN, Brazil

${ }^{5}$ School of Medicine, Christus College, UNICHRISTUS, Fortaleza, CE, Brazil
}

There is growing interest in breeding rheas (Rhea americana) in Brazil. However, there are no data on the yeast microbiota of the gastrointestinal tract of this avian species, and the phenotypic characteristics of these yeasts are not known. Therefore, the aim of this work was to isolate Candida species from the digestive tract of rheas and to evaluate the in vitro antifungal susceptibility and secretion of phospholipases of the recovered isolates. For this purpose, 58 rheas from breeding operations in the cities of Fortaleza and Mossoró, north-eastern Brazil, were used. Samples were gathered from the oropharynx and cloaca of the animals using sterile swabs. Stool samples were collected from their pens by scraping with a scalpel blade. For the primary isolation, the material was seeded onto $2 \%$ Sabouraud dextrose agar supplemented with chloramphenicol $\left(0.5 \mathrm{~g} \mathrm{l}^{-1}\right)$. The isolates were identified based on morphological and biochemical features. After identification, all the strains were submitted to antifungal susceptibility testing for amphotericin B, itraconazole and fluconazole. The phospholipase activity of the Candida species isolates was also tested by culturing on egg yolk agar. Candida species were isolated from at least one anatomical site in 36/58 birds (14/17 juveniles and 22/41 adults) and in 6/10 faecal samples. Mostly, only a single species was isolated from each collection site (36/56 positive sites), with up to three species being observed only in four cases (4/56). A total of 77 isolates were obtained, belonging to the species Candida parapsilosis sensu lato (19), Candida albicans (18), Candida tropicalis (13), Candida guilliermondii (12), Candida krusei (10) and Candida famata (5). C. albicans was more prevalent in the oropharynx of the juvenile rheas when compared with adult ones $(P<0.001)$. All tested isolates were susceptible to amphotericin $\mathrm{B}$, but 16 isolates were simultaneously resistant to the two azole derivatives (11/18 C. albicans, 1/10 C. krusei, 2/19 C. parapsilosis sensu lato and 2/13 C. tropicalis). C. albicans presented a particularly high resistance rate to fluconazole (15/18) and itraconazole (13/18). Finally, 23/77 strains secreted phospholipases. In summary, healthy rheas carry potentially pathogenic Candida species in their gastrointestinal tract, including azole-resistant strains that secrete phospholipases, and are prone to disseminating them in the environment. Thus, breeding and handling these animals may have some implications for human and animal health. 


\section{INTRODUCTION}

The greater rhea (Rhea americana) is a large flightless bird with a close phylogenetic relationship with the ostrich (Struthio camelus), cassowary (Casuarius sp.), emu (Dromaius novaehollandiae) and kiwi (Apteryx australis). The species is native to South America and is found in the wild in many regions of Brazil, despite threats from hunting and habitat destruction (Parizzi et al., 2007; Soares et al., 2010; IUCN, 2012). Rheas are omnivorous, feeding on many plant species, small rodents, reptiles and insects. In recent years, there has been an increase in the number of rhea farms in Brazil to produce meat and feathers.

There are very few studies on the sanitary aspects of commercial breeding of rheas. There is no information on the micro-organisms present in these birds and whether contact with these animals facilitates the dissemination of infectious agents to new hosts and environments. Rheas, as other wild animals, possibly increase the dispersion of ecological niches in the transmission chain of diseases, both to humans and to other animals (Azevedo et al., 2010; Soares et al., 2010). Therefore, it is necessary to investigate animals that are widely dispersed in the wild and also bred in captivity for their possible role as reservoirs of pathogenic micro-organisms, even in the absence of clinical signs of infection.

Yeasts are micro-organisms commonly found in the gastrointestinal microbiota of birds (Mancianti et al., 2002; Melville et al., 2004; Cafarchia et al., 2006a; Brilhante et al., 2010; Costa et al. 2010). There are reports of antifungal resistance among Candida species isolated from healthy cockatiels (Sidrim et al., 2010). The microbiota can vary according to the host species (Melville et al., 2004; Cafarchia et al. 2006b; Brito et al., 2009; Brilhante et al., 2010), but generally there is a high frequency of isolation of Candida species, particularly Candida albicans. To the best of our knowledge, however, there have been no specific studies on the microbiota of Candida species of rheas or the antifungal resistance and virulence of the micro-organisms found. Therefore, the objective of this work was to isolate yeasts of the genus Candida in the microbiota of these birds and to characterize these isolates for resistance to antifungal agents in clinical use and to analyse their production of phospholipases, an important virulence factor commonly detected in yeasts isolated from birds.

\section{METHODS}

Animals. Fifty-eight apparently healthy greater rheas ( $R$. americana) of both sexes, bred in captivity in the cities of Fortaleza, Ceará $\left(3^{\circ} 43^{\prime} 6^{\prime \prime} \mathrm{S}, 38^{\circ} 32^{\prime} 36^{\prime \prime} \mathrm{W}\right)$ and Mossoró, Rio Grande do Norte $\left(5^{\circ} 11^{\prime} 17^{\prime \prime} \mathrm{S}, 37^{\circ} 20^{\prime} 39^{\prime \prime} \mathrm{W}\right)$, north-eastern Brazil, were studied, of which 17 were juveniles ( $\leqslant 12$ months) and 41 adults ( $>12$ months). The birds were physically restrained, and before specimen collection, they were individually evaluated. This study was approved by the Animal Research Ethics Committee of Ceará State University (protocol no. 11044670-4/43).
Sample collection. Samples were collected from two anatomical sites (oropharynx and cloaca) and from droppings. Sterile cotton swabs were used to obtain samples from the oropharynx and cloaca. The swabs were inserted into the anatomical site and rotated. They were then placed into sterile glass slants, containing $1 \mathrm{ml}$ sterile saline $(0.9 \% \mathrm{NaCl})$, keeping the cotton extremity in contact with the solution at $10{ }^{\circ} \mathrm{C}$ until processing, within $12 \mathrm{~h}$. A total of ten stool samples composed of a pool of faeces were collected from the pens where the birds were maintained and were kept at $10{ }^{\circ} \mathrm{C}$ in sterile saline solution until processing, within $12 \mathrm{~h}$.

Isolation and fungal identification procedures. The swabs with samples from the oropharynx and cloaca were inoculated in Petri dishes containing $2 \%$ Sabouraud dextrose agar (Difco Laboratories) with chloramphenicol and incubated at $25{ }^{\circ} \mathrm{C}$ for 10 days, during which the dishes were observed daily for evaluation of the presence of fungal colonies. Previous to streaking the agar plates, the stool samples were processed as described by Brilhante et al. (2010). The cultured media were incubated at $25{ }^{\circ} \mathrm{C}$ for 10 days. For each positive sample, colonies were observed microscopically after Gram staining. For Candida species, the colonies were initially grown on chromogenic medium (HiChrome Candida Differential Agar; HiMedia) for identification of mixed colonies. Afterwards, individual colonies were subcultured onto slants containing potato dextrose agar and Christensen's urea agar, and after $24-48 \mathrm{~h}$, the micro-organisms were grown on cornmeal/Tween 80 agar for morphological analysis. A sugar assimilation test was also performed for each isolate and the results were interpreted according to De Hoog et al. (2000).

Antifungal susceptibility testing. Candida strains were tested against amphotericin B (AMB; Sigma), fluconazole (FLC; Pfizer) and itraconazole (ITC; Janssen Pharmaceutica). The antifungal drugs were diluted according to the guidelines of the Clinical and Laboratory Standards Institute (CLSI, 2008). The concentration range tested was $0.03125-16 \mu \mathrm{g} \mathrm{ml}^{-1}$ for AMB and ITC and 0.125-64 $\mu \mathrm{g} \mathrm{ml}^{-1}$ for FLC (Brito et al., 2009; Sidrim et al., 2010). Inocula were prepared from 2day-old cultures grown on potato dextrose agar at $35{ }^{\circ} \mathrm{C}$ to reach a

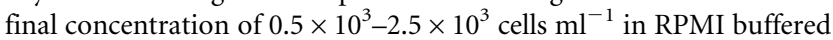
to pH 7 with $0.165 \mathrm{M}$ MOPS, as recommended by CLSI (2008). Susceptibility was investigated by broth microdilution in 96-well microdilution plates at $35{ }^{\circ} \mathrm{C}$ for $48 \mathrm{~h}$. All isolates were tested in duplicate. For AMB, MIC was defined as the lowest concentration at which no growth was observed; for ITC and FLC, MICs were defined as the lowest drug concentration inhibiting fungal growth by $50 \%$ when compared with the control well (CLSI, 2008). Isolates with MICs $>1, \geqslant 64$ and $\geqslant 1 \mu \mathrm{g} \mathrm{ml}^{-1}$ were considered resistant to AMB, FLC and ITC, respectively (CLSI, 2008), except for C. albicans, Candida parapsilosis sensu lato and Candida tropicalis against FLC, which were considered resistant at MIC $\geqslant 8$ (Pfaller, 2012). C. parapsilosis ATCC 22019 was included as a quality control for each test (CLSI, 2008).

Phospholipase experiments. All strains were tested for phospholipase activity $(\mathrm{Pz})$. The test was performed according to Sidrim et al. (2010). Briefly, the medium used was $2 \%$ Sabouraud dextrose agar, supplemented with $1 \mathrm{~mol}$ sodium chloride $1^{-1}, 0.05 \mathrm{~mol}$ calcium chloride $1^{-1}$ and $8 \%$ sterile egg yolk emulsion, at a concentration of $30 \%$. The emulsion was heated to $40{ }^{\circ} \mathrm{C}$ and incorporated into the sterile Sabouraud medium after it reached the same temperature. The medium was poured into $90 \mathrm{~mm}$ Petri dishes and the yeast inoculum was prepared in sterile saline at a concentration of 4 on the McFarland standard scale. The inoculum $(5 \mu \mathrm{l})$ was dripped onto a $5 \mathrm{~mm}$ sterilized filter paper disc, which was then placed on the agar. The plates were then incubated at $35{ }^{\circ} \mathrm{C}$ for 7 days. $\mathrm{Pz}$ was determined by calculating the ratio between the diameter of the yeast colony and the total diameter comprising the colony and the precipitation zone. According to this criterion, when $\mathrm{Pz}=1$, the 
isolate is phospholipase negative; when $1>\mathrm{Pz} \geqslant 0.64$ the isolate is positive for $\mathrm{Pz}$; and when $\mathrm{Pz}<0.64$, the isolate is strongly positive for this enzyme.

Statistical analysis. Fisher's exact test was used to check for differences in the number of isolates between the anatomical sites and bird age ranges (adult versus juvenile). Student's $t$-test for paired samples was used to compare the MICs in relation to the antifungal drugs, as well as for comparisons between the sites in relation to the species isolated. To compare the species irrespective of collection site, analysis of variance was used with post hoc application of Fisher's test. Analysis of variance was also employed to assess differences in the production of phospholipases, both among species and between their isolation sites. Results with $P<0.05$ were considered significant.

\section{RESULTS}

A total of 36/58 rheas were positive for growth of Candida species in at least one of the sites sampled (14/17 for juveniles and 22/41 for adult birds). The positivity per site was 29/58 in the oropharynx and 21/58 in the cloaca. In 14/ 58 animals, Candida species were recovered from both anatomical sites. Six of the ten stool samples were positive.

Only one Candida species was isolated from 39/56 positive samples, whilst in 13/56 cases two species were isolated and in $4 / 56$ cases, three species were isolated (Table 1). Therefore, a total of 77 Candida isolates were obtained, comprising six species, as described in Table 2. The most frequently isolated species were C. parapsilosis sensu lato (19/77) and C. albicans (18/77). C. albicans was significantly more frequent in the oropharynx of juvenile birds than in adults $(P<0.0001)$ (Table 2$)$.

The results obtained from antifungal susceptibility testing are shown in Table 3. There was no resistance to AMB among the isolates. However, 16 strains were resistant to both azole derivatives, namely C. albicans (11/18), Candida krusei (1/10), C. parapsilosis sensu lato (2/19) and C. tropicalis $(2 / 13)$. There was a significant occurrence of resistance among the strains of C. albicans to FLC (15/18) and ITC (13/18). Other isolates showed resistance as follows: C. parapsilosis sensu lato, 7/19 and 3/19 to FLC and ITC, respectively; $C$. tropicalis, $6 / 13$ and $5 / 13$ to FLC and ITC, respectively; Candida guilliermondii, 1/12 to ITC; and C. krusei, 2/10 and 1/10 to FLC and ITC, respectively.

The Pz of the 77 strains of Candida species tested is shown in Table 4. Fifty-four strains were negative $(\mathrm{Pz}=1)$ for the excretion of phospholipase, whilst 18 were positive $(1>\mathrm{Pz}$ $\geqslant 0.64)$ and five were strongly positive $(\mathrm{Pz}<0.64)$. The mean $\mathrm{Pz}$ of the strains that were positive was 0.75 , for $9 / 18$ C. albicans, 1/5 Candida famata, 2/12 C. guilliermondii, 4/ 19 C. parapsilosis sensu lato and 2/13 C. tropicalis. The mean $\mathrm{Pz}$ in strongly positive strains was 0.60 , for $1 / 12 C$. guilliermondii, 3/19 C. parapsilosis sensu lato and 1/13 C. tropicalis. No significant difference was found concerning the secretion of phospholipases by Candida species.

\section{DISCUSSION}

We believe that this is the first study to focus on Candida species isolated from the oropharynx, cloaca and droppings of rheas with the purpose of analysing the occurrence of resistance to antifungals in healthy birds. There have been reports of invasive pulmonary fungal infection in rheas caused by Aspergillus fumigatus (Reissig et al., 2002; Copetti et al., 2004), but there are no data on Candida colonization in healthy rheas.

A high recovery rate of Candida species was observed $(62.07 \%)$, which was much higher than the isolation of yeasts in birds of prey in Europe (25\%; Cafarchia et al., 2006a), similar to that of cockatiels (65\%; Brilhante et al.,

Table 1. Number (\%) of positive samples from oropharynx, cloaca and faeces, grouped according to the species of yeast isolated

\begin{tabular}{|c|c|c|c|c|}
\hline Candida species & Oropharynx & Cloaca & Faeces & Total \\
\hline C. famata & $2(7.0)$ & - & $2(33.3)$ & 4 \\
\hline C. krusei & $2(7.0)$ & $2(9.5)$ & - & 4 \\
\hline C. parapsilosis sensu lato & $2(7.0)$ & $3(14.3)$ & $2(33.3)$ & 7 \\
\hline C. tropicalis & $1(3.4)$ & $5(23.7)$ & - & 6 \\
\hline C. albicans + C. krusei & $1(3.4)$ & - & - & 1 \\
\hline C. albicans + C. parapsilosis & - & $1(4.8)$ & - & 1 \\
\hline C. guilliermondii + C. krusei & $1(3.4)$ & - & - & 1 \\
\hline C. guilliermondii + C. krusei + C. parapsilosis sensu lato & - & $1(4.8)$ & $1(16.7)$ & 2 \\
\hline C. guilliermondii $+C$. krusei $+C$. tropicalis & $1(3.4)$ & - & - & 1 \\
\hline
\end{tabular}


Table 2. Frequency of Candida species according to collection site and animal age

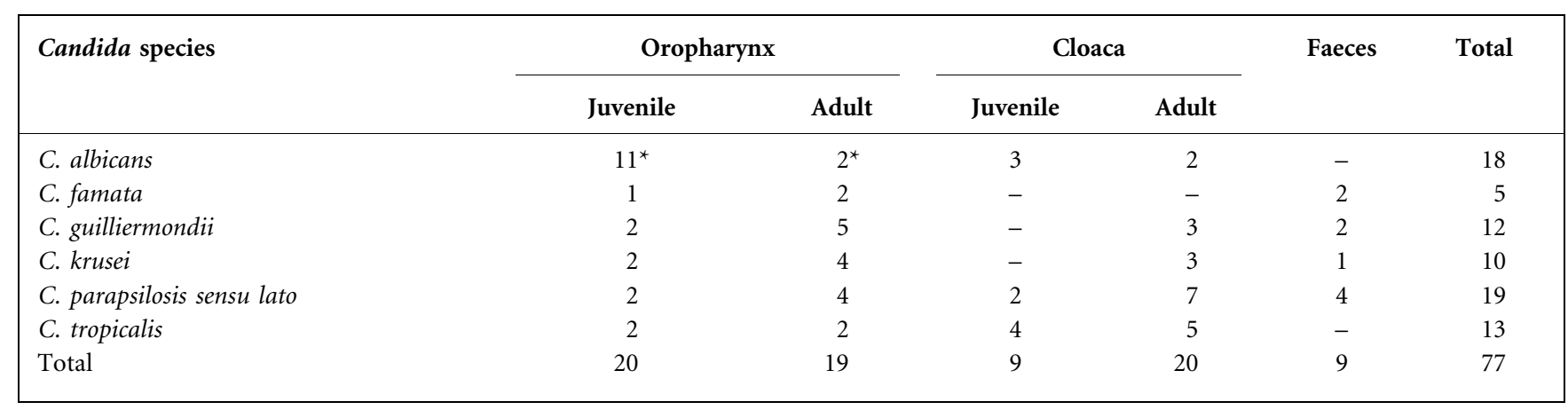

${ }^{\star}$ Statistically significant difference between animal ages $(P<0.05)$.

2010) and lower than that of Brazilian raptors $(72.73 \%$; Brilhante et al. 2012). The isolation rate of Candida species in the oropharynx of the rheas was higher than that observed in ostriches and cockatiels (Melville et al., 2004; Brilhante et al., 2010), and the isolation in the cloaca was higher than in ostriches and migratory birds (Melville et al., 2004; Cafarchia et al., 2006b). Additionally, it was observed that rhea droppings provide a good substrate for colonization by Candida species, as shown by the recovery of this yeast genus from $6 / 10(60 \%)$ samples, greater than the recovery rate observed in studies with other bird species (Mancianti et al., 2002; Cafarchia et al., 2006a; Brilhante et al., 2010). This finding suggests that care should be taken when handling these birds and their excrements.

These differences between the recovery rates of Candida species from different anatomical sites of several avian species are probably associated with species-specific factors, such as the ecology, diet and habitat of these animals (Cafarchia et al., 2006b). In contrast, despite influencing the recovery rate of Candida from different collection sites, these species-specific factors do not seem to influence the composition of the gastrointestinal yeast microbiota, as the species of Candida recovered in this study were similar to other reports concerning other avian groups, such as

Table 3. In vitro antifungal susceptibility of Candida species isolated from the gastrointestinal tract of rheas

GM, Geometric mean; S, sensitive; R, resistant; -, not detected; NC, not calculated because of the small number of strains, which did not allow reliable results.

\begin{tabular}{|c|c|c|c|c|c|c|c|}
\hline \multirow[t]{2}{*}{ Candida species $(n)$} & \multirow[t]{2}{*}{ Drug } & \multirow[t]{2}{*}{ Range } & \multicolumn{3}{|c|}{$\operatorname{MIC}\left(\mu \mathrm{g} \mathrm{ml}^{-1}\right)$} & \multicolumn{2}{|c|}{$\begin{array}{c}\text { Classification } \\
(n)\end{array}$} \\
\hline & & & GM & $\mathrm{MIC}_{50}$ & $\mathrm{MIC}_{90}$ & $S$ & $\mathbf{R}$ \\
\hline \multirow[t]{3}{*}{ C. albicans (18) } & AMB & $0.0625-1$ & 0.25 & 0.25 & 0.55 & 18 & - \\
\hline & FLC & $1->64$ & 33.26 & 64.00 & 128.0 & 3 & 15 \\
\hline & ITC & $0.0625->16$ & 5.879 & 16.00 & 32.00 & 5 & 13 \\
\hline \multirow[t]{3}{*}{ C. famata (5) } & $\mathrm{AMB}$ & $0.03125-0.5$ & 0.125 & $\mathrm{NC}$ & NC & 5 & - \\
\hline & FLC & $0.25-16$ & 3.48 & $\mathrm{NC}$ & $\mathrm{NC}$ & 5 & - \\
\hline & ITC & $0.0625-0.5$ & 0.143 & $\mathrm{NC}$ & NC & 5 & - \\
\hline \multirow[t]{3}{*}{ C. guilliermondii (12) } & $\mathrm{AMB}$ & $0.03125-0.5$ & 0.118 & 0.187 & 0.425 & 12 & - \\
\hline & FLC & $0.5-32$ & 3.175 & 4.0 & 27.20 & 12 & - \\
\hline & ITC & $0.03125->16$ & 0.166 & 0.125 & 22.55 & 11 & 1 \\
\hline \multirow[t]{3}{*}{ C. krusei (10) } & $\mathrm{AMB}$ & 0.0625-1 & 0.25 & 0.25 & 0.95 & 10 & - \\
\hline & FLC & $0.125->64$ & 4.287 & 2.00 & 121.6 & 8 & 2 \\
\hline & ITC & $0.0625->16$ & 0.267 & 0.187 & 28.85 & 9 & 1 \\
\hline \multirow[t]{3}{*}{ C. parapsilosis sensu lato (19) } & $\mathrm{AMB}$ & $0.03125-0.5$ & 0.12 & 0.125 & 0.25 & 19 & - \\
\hline & FLC & $0.125->64$ & 2.489 & 4.0 & 32.0 & 12 & 7 \\
\hline & ITC & $0.03125->16$ & 0.268 & 0.125 & 32.0 & 16 & 3 \\
\hline \multirow[t]{3}{*}{ C. tropicalis (13) } & $\mathrm{AMB}$ & $0.03125-1$ & 0.146 & 0.125 & 0.8 & 13 & - \\
\hline & FLC & $0.125-32$ & 3.232 & 4.0 & 32.0 & 7 & 6 \\
\hline & ITC & $0.0625->16$ & 1.0 & 0.25 & 32.00 & 8 & 5 \\
\hline
\end{tabular}


Table 4. Pz of the Candida species strains

\begin{tabular}{|c|c|c|c|c|}
\hline \multirow[t]{2}{*}{ Candida species } & \multirow[t]{2}{*}{$n$} & \multicolumn{2}{|c|}{$\mathrm{Pz}[$ mean $\pm \mathrm{SD}(n)]$} & \multirow{2}{*}{$\begin{array}{l}\text { No. negative isolates } \\
\qquad(\mathrm{Pz}=1)\end{array}$} \\
\hline & & Positive isolates $(1>P z \geqslant 0.64)$ & Strongly positive isolates $(\mathrm{Pz}<0.64)$ & \\
\hline C. famata & 5 & $0.65(1)$ & - & 4 \\
\hline C. guilliermondii & 12 & $0.77 \pm 0.14$ & $0.55(1)$ & 9 \\
\hline C. tropicalis & 13 & $0.85 \pm 0.07(2)$ & $0.61(1)$ & 10 \\
\hline Total & 77 & $0.75 \pm 0.09(18)$ & $0.60 \pm 0.03(5)$ & 54 \\
\hline
\end{tabular}

ostriches (Melville et al., 2004), psittacines (Vieira \& Coutinho, 2009; Brilhante et al., 2010) and raptors (Brilhante et al., 2012).

C. parapsilosis sensu lato was the most prevalent species in this study, occurring in both anatomical sites of young and adult animals. This yeast is an emerging pathogen that has become more prevalent in humans and animals in recent years. It is the non- $C$. albicans species that has been most often reported in cases of invasive candidiasis, mainly in immunocompromised individuals (Trofa et al., 2008; Lord et al., 2010). In recent studies, it was shown that, of 141 bloodstream isolates tested in Brazil, $88 \%$ were $C$. parapsilosis, 9\% Candida orthopsilosis and 3\% Candida metapsilosis (Gonçalves et al., 2010), whilst in Spain, of 293 isolates recovered from cases of invasive candidiasis, $74.4 \%$ were C. parapsilosis, $23.54 \%$ were C. orthopsilosis and $2.05 \%$ were C. metapsilosis (Garcia-Effron et al., 2012). However, the distribution of strains from veterinary sources among the three species of the C. parapsilosis species complex is still unknown. Thus, additional studies will be performed in order to further identify these strains.

C. albicans was the second most frequent species in this study and has been reported as the most common Candida sp. among avian hosts (Garner et al., 2010), being widely recovered from several different bird species, such as ostriches (Melville et al., 2004), cockatiels (Brilhante et al., 2010) and raptors (Brilhante et al., 2012). A greater frequency of $C$. albicans in the oropharynx of birds, as observed here, has also been reported by other authors (Melville et al., 2004; Brilhante et al., 2010), suggesting that this yeast is one of the main components of the microbiota of this anatomical site in avian species. In humans, $C$. albicans is often isolated in both healthy and sick hosts and is the most common species in infections, accounting for over half of invasive candidiasis cases (Lass-Flörl, 2009; Lord et al., 2010).

Other non- $C$. albicans species have increasingly been reported in human and animal infections, sometimes being classified as emerging pathogens (Deem, 2003; DesnosOllivier et al., 2008; Lord et al., 2010). Several of these species were isolated in this study, such as C. famata, C. guilliermondii, C. tropicalis and C. krusei. C. famata is considered to be a non-pathogenic commensal yeast, but has been reported in infections of the ocular system and central nervous system and in cases of candidaemia (Nawange et al., 2010). C. guilliermondii has been reported in superficial infections, such as onychomycosis, and, rarely, in invasive infections, including bone infections and candidaemia (Pfaller et al., 2006). C. tropicalis is among the most mentioned non-C. albicans species involved in infections (Ortega et al., 2011), and can be isolated from cancer patients, intensive care units and post-operative patients. It caused the highest mortality in cases of candidaemia, when compared with the other Candida species in a study carried out in Italy (Tortorano et al., 2002; Ortega et al., 2011). C. krusei is involved in around $4 \%$ of infections by members of the genus Candida, being isolated more often from patients with blood disorders, from transplant patients and from patients who have previously been exposed to azole-based antifungals (Ortega et al., 2011).

Predominantly, collection sites were colonized by one single species (69.64\% of positive samples). In turn, two Candida species were in found in $23.21 \%$ of the samples and three were found in $7.14 \%$. The same pattern has been observed in other bird species (Melville et al., 2004; Cafarchia et al., 2006a; Vieira \& Coutinho, 2009; Brilhante et al., 2010). The predominance of a single yeast species in most collection sites suggests that some species are able to inhibit colonization by others and, as demonstrated by Brilhante et al. (2010), C. albicans was most commonly found as the only species in a given collection site. This ability to inhibit the growth of other species may contribute to the overgrowth of a certain strain, as microbial competition will be reduced, leading to the development of a Candida infection, especially when predisposing factors are present. This mechanism is probably involved in the capacity of $C$. albicans to be particularly pathogenic in immunocompromised hosts (Rodríguez-Galán et al., 2010). Considering the high recovery rate of Candida species, breeders should be aware of changes in the parasite-host balance, as some factors such as stress, poor sanitation, overcrowding and poor nutrition among confined animals favour the multiplication of these micro-organisms and facilitate their 
dissemination from the colonized sites, leading to the development of infection (Vieira \& Coutinho, 2009; Rodríguez-Galán et al., 2010).

Regarding the in vitro antifungal susceptibility, no isolates were resistant to amphotericin $\mathrm{B}$, showing that the strains recovered from rheas react to this drug similarly to those isolated from other healthy animals (Brito et al., 2009; Sidrim et al., 2010; Brilhante et al., 2011, 2012).

In contrast, a substantial resistance to azole derivatives was observed among the Candida species assessed in the present study. Isolates of C. albicans, C. krusei, C. parapsilosis sensu lato and $C$. tropicalis presented resistance to both azole drugs tested. This finding is particularly important because all of these species have been implicated as human or animal pathogens (Deem, 2003; Lord et al., 2010; Sidrim et al., 2010). Additionally, resistance to ITC in isolates of C. guilliermondii was also observed. The high resistance rate to azole derivatives among Candida species in this study corroborates the results of other studies with Candida species from healthy animals and environmental sources (Brito et al., 2009; Lord et al., 2010; Sidrim et al., 2010; Brilhante et al., 2011, 2012).

Resistance to azole derivatives is fundamentally linked to changes in gene sequence or expression and, as a rule, appears to be due to selective pressures induced by exposure to the azole products used in clinical practice or in agriculture (Kanafani \& Perfect, 2008; Brilhante et al., 2012; Pfaller, 2012). As the animals evaluated in this study had no history of prior treatment with antifungal drugs, the resistance may be associated with the presence of these compounds in the feed or fruits given to these animals, as the occurrence of cross-resistance to medical and agricultural azoles in Candida species has already been reported (Müller et al., 2007).

The mean $\mathrm{Pz}$ activity in the Candida species of this study was lower than observed in studies with Candida species from other avian species (Cafarchia et al., 2008; Vieira \& Coutinho, 2009; Sidrim et al., 2010) and from healthy humans (Oksuz et al., 2007). Some authors have observed a correlation between resistance to FLC and secretion of phospholipases (Ying \& Chunyang, 2012). This might have occurred in our study, where $>80 \%$ of the C. albicans strains were resistant to FLC and $50 \%$ were positive for production of this enzyme. Non-C. albicans species in a smaller proportion also secreted phospholipases, including strains of C. guilliermondii, C. parapsilosis sensu lato and C. tropicalis.

Even though Candida species are considered commensal organisms and compose the microbiota of the gastrointestinal tract of birds, they are capable of causing disease whenever an impairment of the immune system is established. In recent years, the incidence of opportunistic mycoses, especially those caused by Candida species, has increased (Pfaller \& Diekema, 2007). In addition, it has been suggested that animals should be considered potential sources of Candida species infections for humans, mainly immunocompromised individuals (Edelmann et al., 2005). Thus, based on these assumptions, the recovery of resistant Candida isolates capable of producing phospholipase from the gastrointestinal tract is important with regard to the possible transmission of resistant strains from these animals to humans.

\section{CONCLUSION}

Healthy rheas ( $R$. americana) carry potentially pathogenic Candida species in their gastrointestinal tract, including azole-resistant strains that secrete phospholipases, and are prone to disseminating them in the environment. Thus, breeding and handling of these animals may have some implications for human and animal health.

\section{ACKNOWLEDGEMENTS}

This work was supported by grants from the National Council for Scientific and Technological Development (CNPq; Brazil; Processes 302574/2009-3, 562296/2010-7, 481614/2011-7, 504189/2012-3) and the Coordination Office for the Improvement of Higher Education Personnel (CAPES/PNPD 2103/2009).

\section{REFERENCES}

Azevedo, C. S., Ferraz, J. B., Tinoco, H. P., Young, R. J. \& Rodrigues, M. (2010). Time-activity budget of greater rheas (Rhea americana, Aves) on a human-disturbed area: the role of habitat, time of the day, season and group size. Acta Ethol 13, 109-117.

Brilhante, R. S. N., Castelo-Branco, D. S., Soares, G. D. P., AsteteMedrano, D. J., Monteiro, A. J., Cordeiro, R. A., Sidrim, J. J. C. \& Rocha, M. F. G. (2010). Characterization of the gastrointestinal yeast microbiota of cockatiels (Nymphicus hollandicus): a potential hazard to human health. J Med Microbiol 59, 718-723.

Brilhante, R. S. N., Paiva, M. A. N., Sampaio, C. M. S., Teixeira, C. E. C., Castelo-Branco, D. S. C. M., Leite, J. J. G., Moreira, C. A., Silva, L. P., Cordeiro, R. A. \& other authors (2011). Yeasts from Macrobrachium amazonicum: a focus on antifungal susceptibility and virulence factors of Candida spp. FEMS Microbiol Ecol 76, 268277.

Brilhante, R. S. N., Castelo-Branco, D. S. C. M., Duarte, G. P. S., Paiva, M. A. N., Teixeira, C. E. C., Zeferino, J. P. O., Monteiro, A. J., Cordeiro, R. A., Sidrim, J. J. C. \& Rocha, M. F. G. (2012). Yeast microbiota of raptors: a possible tool for environmental monitoring. Environ Microbiol Rep 4, 189-193.

Brito, E. H. S., Fontenelle, R. O. S., Brilhante, R. S. N., Cordeiro, R. A., Monteiro, A. J., Sidrim, J. J. C. \& Rocha, M. F. G. (2009). The anatomical distribution and antimicrobial susceptibility of yeast species isolated from healthy dogs. Vet J 182, 320-326.

Cafarchia, C., Romito, D., latta, R., Camarda, A., Montagna, M. T. \& Otranto, D. (2006a). Role of birds of prey as carriers and spreaders of Cryptococcus neoformans and other zoonotic yeasts. Med Mycol 44, 485-492.

Cafarchia, C., Camarda, A., Romito, D., Campolo, M., Quaglia, N. C., Tullio, D. \& Otranto, D. (2006b). Occurrence of yeasts in cloacae of migratory birds. Mycopathologia 161, 229-234. 
Cafarchia, C., Romito, C., Coccioli, C., Camarda, A. \& Otranto, D. (2008). Phospholipase activity of yeasts from wild birds and possible implications for human diseases. Med Mycol 46, 1-6.

CLSI (2008). Reference Method for Broth Dilution Antifungal Susceptibility Testing of Yeasts; Approved Standard M27-A3, 3rd edn., Wayne, PA: Clinical and Laboratory Standards Institute.

Copetti, M. V., Segabinazi, S. D., Flores, M. L., Alves, S. H. \& Santurio, J. M. (2004). Pulmonary aspergillosis outbreak in Rhea americana in southern Brazil. Mycopathologia 157, 269-271.

Costa, A. K. F., Sidrim, J. J. C., Cordeiro, R. A., Brilhante, R. S. N., Monteiro, A. J. \& Rocha, M. F. G. (2010). Urban pigeons (Columba livia) as a potential source of pathogenic yeasts: a focus on antifungal susceptibility of Cryptococcus strains in Northeast Brazil. Mycopathologia 169, 207-213.

De Hoog, G. S., Guarro, J., Gené, J. \& Figueiras, M. J. (2000). Atlas of Clinical Fungi. Utrecht: Centraalbureau voor Schimmslcultures.

Deem, S. L. (2003). Fungal diseases of birds of prey. Vet Clin North Am Exot Anim Pract 6, 363-376.

Desnos-Ollivier, M., Ragon, M., Robert, V., Raoux, D., Gantier, J. C. \& Dromer, F. (2008). Debaryomyces hansenii (Candida famata), a rare human fungal pathogen often misidentified as Pichia guilliermondii (Candida guilliermondii). J Clin Microbiol 46, 3237-3242.

Edelmann, A., Krüger, M. \& Schmid, J. (2005). Genetic relationship between human and animal isolates of Candida albicans. J Clin Microbiol 43, 6164-6166.

Garcia-Effron, G., Canton, E., Pemán, J., Dilger, A., Romá, E. \& Perlin, D. S. (2012). Epidemiology and echinocandin susceptibility of Candida parapsilosis sensu lato species isolated from bloodstream infections at a Spanish university hospital. J Antimicrob Chemother 67, 2739-2748.

Garner, C. D., Starr, J. K., McDonough, P. L. \& Altier, C. (2010), Molecular identification of veterinary yeast isolates by use of sequence-based analysis of the D1/D2 region of the large ribosomal subunit. J Clin Microbiol 48, 2140-2146.

Gonçalves, S. S., Amorim, C. S., Nucci, M., Padovan, A. C. B., Briones, M. R. S., Melo, A. S. A. \& Colombo, A. L. (2010). Prevalence rates and antifungal susceptibility profiles of the Candida parapsilosis species complex: results from a nationwide surveillance of candidaemia in Brazil. Clin Microbiol Infect 16, 885-887.

IUCN (2012). Bird Life international 2012. Rhea americana. IUCN Red List of Threatened Species, version 2012.2. http://www.iucnredlist.org

Kanafani, Z. A. \& Perfect, J. R. (2008). Antimicrobial resistance: resistance to antifungal agents: mechanisms and clinical impact. Clin Infect Dis 46, 120-128.

Lass-Flörl, C. (2009). The changing face of epidemiology of invasive fungal disease in Europe. Mycoses 52, 197-205.

Lord, A. T. K., Mohandas, K., Somanath, S. \& Ambu, S. (2010). Multidrug resistant yeasts in synanthropic wild birds. Ann Clin Microbiol Antimicrob 9, 11.

Mancianti, F., Nardoni, S. \& Ceccherelli, R. (2002). Occurrence of yeasts in psittacines droppings from captive birds in Italy. Mycopathologia 153, 121-124.

Melville, P. A., Cogliati, B., Mangiaterra, M. B. B. C. D., Peres, M. R., Moura, S. C. A., Matsuda, L., Kim, A. \& Benites, N. R. (2004). Determinação da microbiota presente na cloaca e orofaringe de avestruzes (Struthio camelus) clinicamente sadios. Ciência Rural 34, $1871-1876$.

Müller, F. M. C., Staudigel, A., Salvenmoser, S., Tredup, A., Miltenberger, R. \& Herrmann, J. V. (2007). Cross-resistance to medical and agricultural azole drugs in yeasts from the oropharynx of human immunodeficiency virus patients and from environmental Bavarian vine grapes. Antimicrob Agents Chemother 51, 3014-3016.

Nawange, S. R., Singh, K., Naidu, J. \& Singh, S. M. (2010). Naturally acquired systemic dual infection caused by Candida famata (Debaryomyces hansenii) and Candida catenulata in albino rats bred for sale in the market at Jabalpur (Madhya Pradesh), India. Mycoses 53, 173-175.

Oksuz, S., Sahin, I., Yildirim, M., Gulcan, A., Yavuz, T., Kaya, D. \& Koc, A. N. (2007). Phospholipase and proteinase activities in different Candida species isolated from anatomically distinct sites of healthy adults. Jpn J Infect Dis 60, 280-283.

Ortega, M., Marco, F., Soriano, A., Almela, M., Martínez, J. A., López, J., Pitart, C. \& Mensa, J. (2011). Candida species bloodstream infection: epidemiology and outcome in a single institution from 1991 to 2008. J Hosp Infect 77, 157-161.

Parizzi, R. C., Miglino, M. A., Maia, M. O., Souza, J. A., Santos, J. M., Oliveira, M. F. \& Santos, T. C. (2007). Morfologia do ovário da ema (Rhea americana). Pesqui Vet Bras 27, 89-94.

Pfaller, M. A. (2012). Antifungal drug resistance: mechanisms, epidemiology, and consequences for treatment. Am J Med 125 (Suppl.), S3-S13.

Pfaller, M. A. \& Diekema, D. J. (2007). Epidemiology of invasive candidiasis: a persistent public health problem. Clin Microbiol Rev 20, 133-163.

Pfaller, M. A., Diekema, D. J., Mendez, M., Kibbler, C., Erzsebet, P., Chang, S.-C., Gibbs, D. L., Newell, V. A. \& Global Antifungal Surveillance Group (2006). Candida guilliermondii, an opportunistic fungal pathogen with decreased susceptibility to fluconazole: geographic and temporal trends from the ARTEMIS DISK antifungal surveillance program. J Clin Microbiol 44, 3551-3556.

Reissig, E. C., Uzal, F. A., Schettino, A. \& Robles, C. A. (2002). Pulmonary aspergillosis in a great rhea (Rhea americana). Avian Dis 46, 754-756.

Rodríguez-Galán, M. C., Sotomayor, C. E., Cano, R., Porporatto, C., Renna, M. S., Paraje, M. G., Cejas, H. \& Correa, S. G. (2010). Immune neuroendocrine interactions during a fungal infection in immunocompetent or immunosuppressed hosts. Neuroimmunomodulation 17, 188-191.

Sidrim, J. J. C., Maia, D. C. B. S. C., Brilhante, R. S. N., Soares, G. D. P., Cordeiro, R. A., Monteiro, A. J. \& Rocha, M. F. G. (2010). Candida species isolated from the gastrointestinal tract of cockatiels (Nymphicus hollandicus): in vitro antifungal susceptibility profile and phospholipase activity. Vet Microbiol 145, 324-328.

Soares, H. S., Alves, N. D., Pereira, R. H. M. A., Matos, S. M., Pena, H. F. J., Gennari, S. M., Feijó, F. M. C., Amóra, S. S. A. \& Peixoto, G. C. X. (2010). Ocorrência de anticorpos anti-Toxoplasma gondii em emas (Rhea americana) do Centro de Multiplicação de Animais Silvestres de Mossoró, Rio Grande do Norte. Arq Bras Med Vet Zootec 62, 489-491.

Tortorano, A. M., Biraghi, E., Astolfi, A., Ossi, C., Tejada, M., Farina, C., Perin, S., Bonaccorso, C., Cavanna, C. \& other authors (2002). European Confederation of Medical Mycology (ECMM) prospective survey of candidaemia: report from one Italian region. J Hosp Infect 51, 297-304.

Trofa, D., Gácser, A. \& Nosanchuk, J. D. (2008). Candida parapsilosis, an emerging fungal pathogen. Clin Microbiol Rev 21, 606-625.

Vieira, R. G. \& Coutinho, S. D. A. (2009). Phenotypical characterization of Candida spp. isolated from crop of parrots (Amazona spp.). Pesqui Vet Bras 29, 452-456.

Ying, S. \& Chunyang, L. (2012). Correlation between phospholipase of Candida albicans and resistance to fluconazole. Mycoses 55, 50-55. 